\title{
NORDIC \\ BIOECONOMY PROGRAMME
}
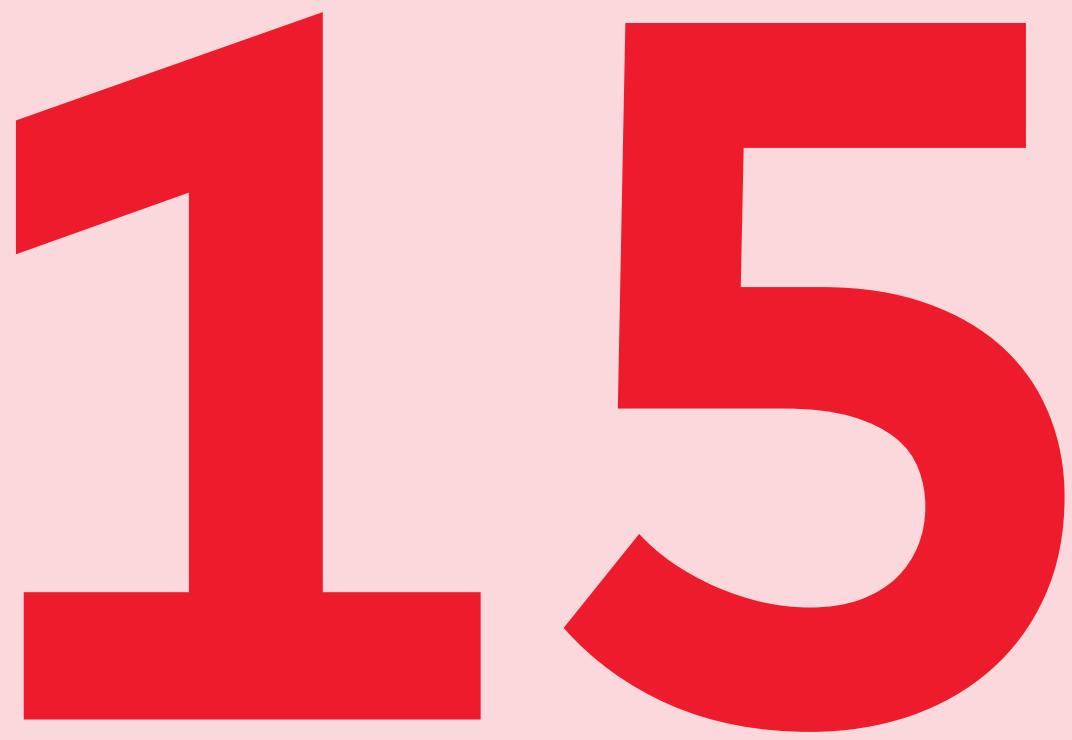

ACTION POINTS

FOR SUSTAINABLE

CHANGE

(1) Nordic Council of Ministers 
Nordic Bioeconomy Programme

15 Action Points for Sustainable Change

ANP 2018:785

ISBN 978-92-893-5662-6 (PRINT)

ISBN 978-92-893-5663-3 (PDF)

ISBN 978-92-893-5661-9 (EPUB)

http://dx.doi.org/10.6027/ANP2018-785

(C) Nordic Council of Ministers 2018

Layout: Louise Jeppesen

Print: Rosendahls

Printed in Denmark

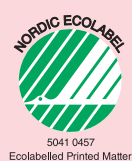

\section{Nordic co-operation}

Nordic co-operation is one of the world's most extensive forms of regional collaboration, involving Denmark, Finland, Iceland, Norway, Sweden, the Faroe Islands, Greenland, and Åland.

Nordic co-operation has firm traditions in politics, the economy, and culture. It plays an important role in European and international collaboration, and aims at creating a strong Nordic community in a strong Europe.

Nordic co-operation seeks to safeguard Nordic and regional interests and principles in the global community. Shared Nordic values help the region solidify its position as one of the world's most innovative and competitive.

Nordic Council of Ministers

Nordens Hus

Ved Stranden 18

DK-1061 Copenhagen K

www.norden.org

Download and order Nordic publications from www.norden.org/nordpub 


\section{NORDIC BIOECONOMY PROGRAMME}
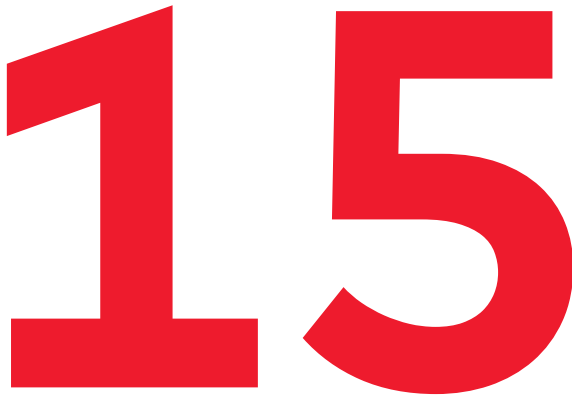

\section{ACTION POINTS FOR SUSTAINABLE CHANGE}

\section{Contents}

5 Preface

7 Executive summary

10 Introduction - global perspectives

13 The Nordic bioeconomy - where are we now?

1715 actions to make the "new" Nordic bioeconomy a reality

19 INNOVATION

Supporting research, innovation and human capital

21 POLICIES

Driving market development

23 NETWORKS

Forging new and stronger connections

25 The way forward

26 Appendix: 5 Principles for a sustainable Nordic Bioeconomy 


\section{Preface}

The Nordic bioeconomy programme presented in this document brings together environmental, social and economic ambitions for a more sustainable Nordic Region. We are facing a new era of the bioeconomy, in which new industries will be built, new jobs created, and new standards for resource efficiency achieved. A new era in which, if we do it right, primary production will also have the potential to benefit from the added value generated from upgrading biomass to more valuable products, and bio-based and food industries will have opportunities to be more competitive.

To contribute to this development, the Nordic Council of Ministers convened the Nordic Bioeconomy Panel in 2014 under the Icelandic Presidency. The primary objective of the panel was to propose a strategic programme for the Nordic bioeconomy. The programme has been discussed at several meetings of the panel, as well as of relevant councils of ministers and committees of senior officials. This document presents the outcomes in the form of a range of activities aimed at promoting the bioeconomy in the Nordic Region and beyond, primarily focusing on the period 2018-2022. It seeks to facilitate the development of new value chains and guide the transition of traditional bio-based industries into technologically advanced industries, and to optimise the production and value creation of biomass.

The Nordic Region occupies a valuable and relatively unique position in the world - one that brings many opportunities and responsibilities. The Nordic countries have a global responsibility to contribute to the necessary sustainable transition of our societies, and to develop new bio-based technologies and solutions that contribute to a more sustainable future.

It is a privilege for me, as the chair of the Nordic Council of Ministers for Fisheries, Aquaculture, Agriculture, Food and Forestry in 2018 to present this strategic programme. It is my sincerely held belief, that it will provide us all with very relevant guidelines for progress towards a more prosperous and sustainable future.

\section{Sven-Erik Bucht}

Minister for Rural Affairs, Sweden

The Swedish Presidency of the Nordic Council of Ministers 2018 


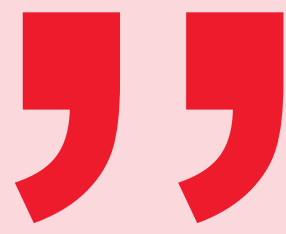

The Nordic Region has the potential to become selfsufficient in biofuels for transport 


\section{Executive summary}

The Nordic Bioeconomy Programme presented in this document combines environmental, social and economic ambitions for a more sustainable Nordic Region. The bioeconomy is of fundamental importance to the national economies of the Nordic countries, and especially important for rural development in large parts of the Region. The programme aims to create new industries and value chains and to facilitate and guide the transition of traditional bio-based industries (agriculture, forestry and fishery processing) into technologically advanced industries and small and medium-sized enterprises (SMEs). It also aims to optimise the use of biomass in order to unlock its full potential and generate value. The overarching aim of the programme is to contribute to the rapid development of the Nordic bioeconomy through strong policy support at both national and Nordic level. The programme sets out a vision for the Nordic bioeconomy based on four pillars:

- Competitive bio-based industries

- Sustainable resource management

- Resilient and diverse ecosystems

- Inclusive economic development

In order to realise this vision, a detailed action plan defines a number of deliverables. These are grouped into three categories - INNOVATE, ACCELERATE and NETWORK - that reflect the main areas in which a Nordic approach can add value to national bioeconomy strategies and initiatives. Together, these actions represent a starting point for progress towards a more competitive and sustainable Nordic bioeconomy. 


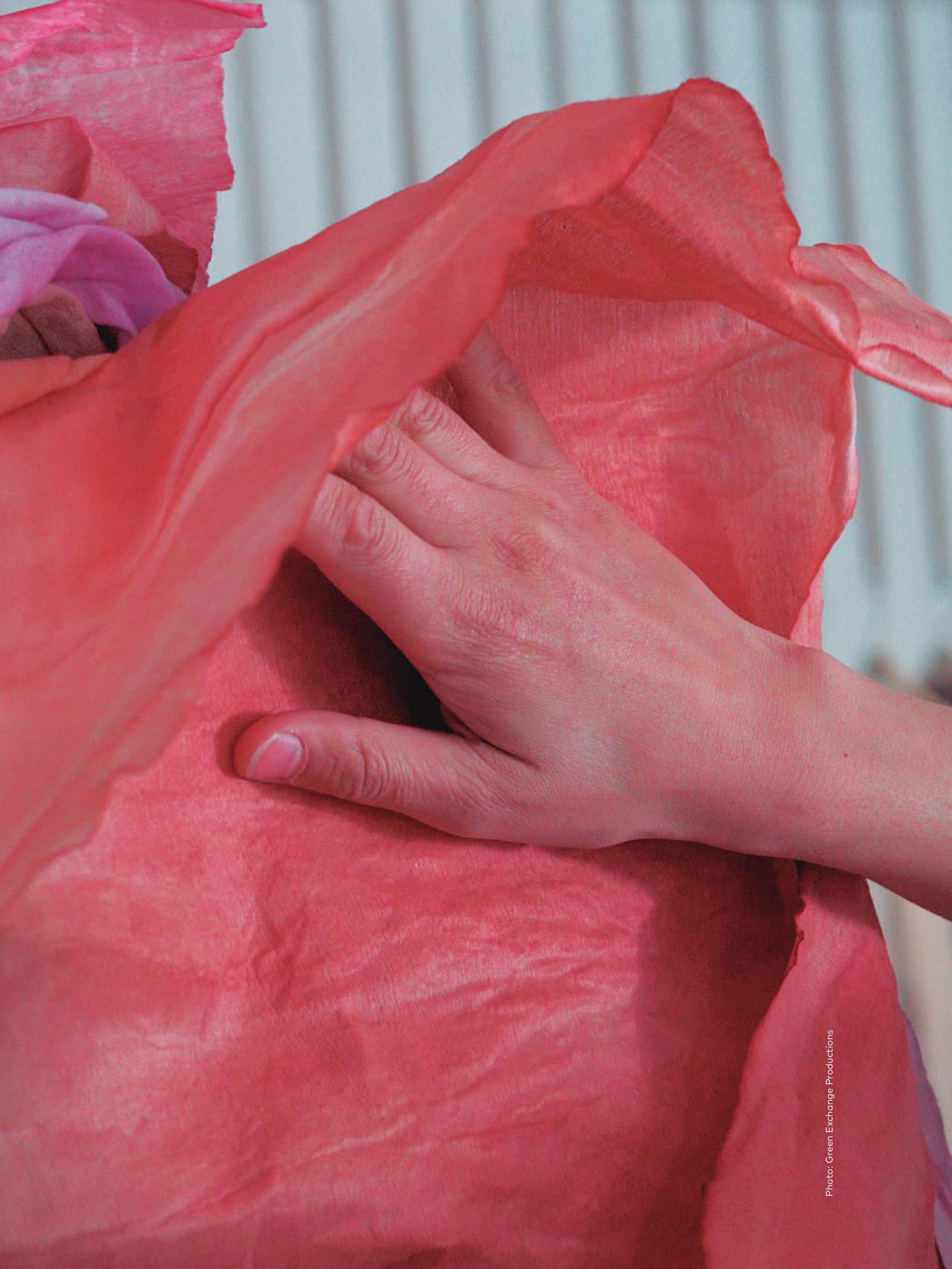




\section{ACTION POINTS}

\section{INNOVATE}

Supporting research, innovation and human capital

\section{ACCELERATE}

Policies and market development
1. Increased R\&D funding

2. More coherent policies

3. Investment support

4. New educational opportunities

5. Provide intelligence
6. Targeted public procurement

7. Regulatory frameworks

8. Labelling and certificates

9. Regional innovation strategies

10. Promote cross-border freedom of movement

\section{NETWORK}

Forging new and stronger connections
11. Support bioeconomy clusters

12. Open access to test and demonstration centres

13. Macro-regional co-operation

14. Bolstering networking activities

15. Nordic impact and branding 


\title{
Introduction - global perspectives
}

\begin{abstract}
The bioeconomy encompasses the utilisation of renewable biological resources and the conversion of these resources (including side- and waste streams) into value-added products, technology and services. The products include food, feed, bio-based products, chemicals, materials and bioenergy, while services include, for example, water and air quality, shelter and recreation (e.g. walking, skiing and foraging for berries and mushrooms) and nonanthropogenic outcomes like biodiversity. The bioeconomy has always, therefore, been an integral part of human activity, but it is only recently that the term was coined and specifically defined. The definition focuses on the better management of the carbon cycle related to human activities and the interplay between food, energy and other bio-based goods. The key question is how the biological sectors can contribute to serving the needs of growing populations and mitigating climate change through the replacement of fossil-based products and an improved use of global resources.
\end{abstract}

\section{"The bioeconomy can contribute significantly to the United Nations COP process and to reaching the 17 Sustainable Development Goals for 2030"}

The bioeconomy has the potential to replace many of the fossilbased products (energy, materials and chemicals) upon which we are so heavily reliant, and to reduce the carbon footprint of food and feed by increasing resource efficiency and upgrading side-streams. In this way, the bioeconomy can contribute significantly to the United Nations COP process and to reaching the 17 Sustainable Development Goals for 2030. However, a precondition for this is that the development of the bioeconomy prioritises long-term sustainability in terms of resource management, biodiversity and inclusive growth. The sustainability principles outlined in appendix of this document set out the overarching criteria for a sustainable bioeconomy.

Naturally, bio-resources from forestry, agriculture and fisheries are often found in rural areas. On the other hand, food waste is more often concentrated in urban areas. The development of the bioeconomy requires a well-educated and competent work force with many skills and offers opportunities for young people to either stay in or move to the rural regions. 
These opportunities are especially important for women, who often struggle to find suitable employment in rural areas. In some regions of the world, the bioeconomy is seen as an important factor in maintaining a degree of selfsufficiency in terms of energy, food, feed and fibres, and contributing to increased resilience and security.

The development of the bioeconomy is also linked to the ownership of natural resources. It is important to ensure that all partners in the value chain get their fair share of the added value. Here, special attention must be paid to areas where the primary producers - who are in many cases the caretakers of the natural resources - occupy a relatively weak bargaining position. In addition, the utilisation of land, fresh water and oceans is not only a matter of technology and competition for resources, but also about the recreational and other interests of local people, which should be taken into consideration in order to secure legitimacy and ensure balanced utilisation.

The Nordic Bioeconomy Panel has set out its vision for the development of the bioeconomy in the Nordic Region. The vision emphasises the multifaceted nature of the bioeconomy and the constraints that must be respected in order to ensure sustainability and inclusive development.

The following four points summarise the vision for the Nordic Bioeconomy:

- Competitive bio-based industries

- Sustainable resource management

- Resilient and diverse ecosystems

- Inclusive economic development 


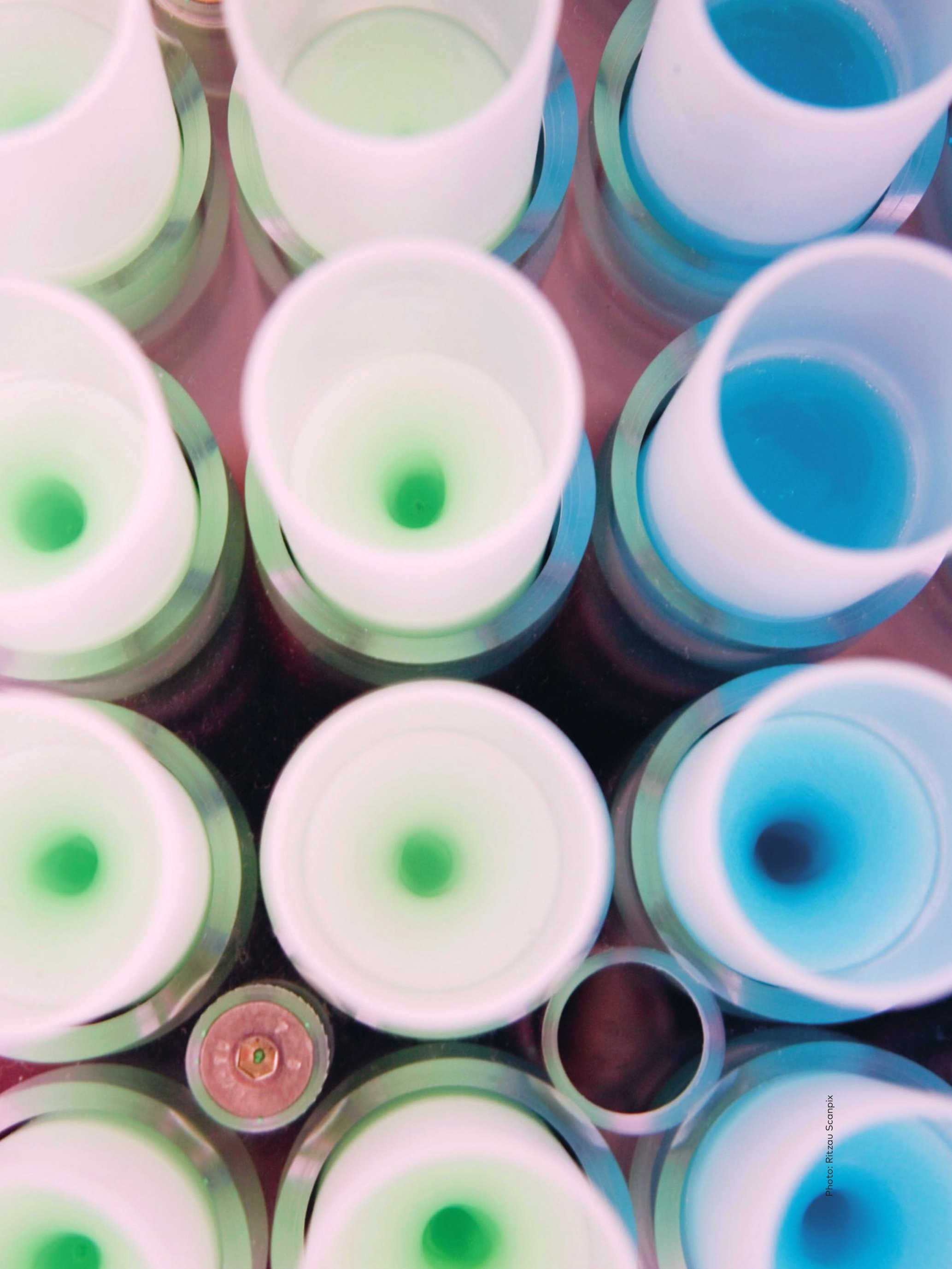




\section{The Nordic bioeconomy - where are we now?}

The bioeconomy plays a major role in the economy of all of the Nordic countries. The Region combines a diverse abundance of both terrestrial and aquatic bioresources with a high level of technological advancement, competitive advantages in core bioeconomy technologies, good infrastructure and a welleducated population. There is also vast knowhow on policy instruments, local management schemes and ownership regimes for the different bio-resources that are essential for local and sustainable management. In addition, there is a unique public awareness of stewardship, responsibilities and knowledge about sustainability, which is useful when it comes to policy implementation. The same is true of openness to new technology, like nano-technology and cognitive sciences, to name but two of the trendsetting disciplines.

The Nordic Region is a major producer of primary biomass - approximately $30 \%$ of Europe's forest production and more than $50 \%$ of the total marine harvest in Europe come from the Nordic Region. ${ }^{1}$ This also means that the Nordic countries - especially the rural regions - are highly dependent on the bioeconomy. It represents $15-20 \%$ of exports from most of the Nordic countries (a far greater proportion in Iceland, Greenland and the Faroe Islands), and approximately $10 \%$ of total economic activity in the Region. ${ }^{2}$ The Nordic countries also have huge potential in terms of food production and reduction of food waste as 3.5

\author{
"The Nordic countries \\ also have huge potential in \\ terms of food production \\ and reduction of food \\ waste as $\mathbf{3 . 5}$ million tonnes \\ of food are wasted in the \\ Region every year"
} million tonnes of food are wasted in the Region every year.

This diversity in biomass reflects the Nordic Region's strengths rather than challenges. Firstly, in almost all biomass value chains, the Nordic Region is in a position of strength in terms of both market position and the development of knowledge technology. The Region also has a strong tradition of managing access to land, e.g. the freedom to roam in most Nordic countries is a strong asset in relation to how the land is used.

\footnotetext{
${ }^{1}$ Agriculture, Forestry and Fisheries statistics. Eurostat 2016.

2 State of the Nordic Region 2018.
} 
The diversity of biomass enables the parallel development of all relevant value chains, bringing together the many research and innovation communities, primary production, industries and SMEs within more effective collaborative networks. The technologies and knowhow behind such activities as biorefining or the recycling of biomass (e.g. grass, seaweed or algae) in one sector could be shared with researchers and companies in other sectors and other regions.

\section{"One of the keys to the development of the bioeconomy is to improve resource efficiency by unlocking the full potential of biomass"}

One of the keys to the development of the bioeconomy is to improve resource efficiency by unlocking the full potential of biomass. This will entail addressing challenges in identifying profitable and extractable value-added products from the complexity of the biomass components (e.g. utilising the complex structures of biofibres and organic molecules for applications in new materials and special chemicals). Resource efficiency, as an integral guiding principle of the growing, versatile bioeconomy, also encompasses recovering the higher value components before processing for production of e.g. bioenergy or soil improvement products.

With regard to public policy, all of the Nordic countries have developed their own national strategic approaches to the bioeconomy - although these differ in both form and content. Some countries and regions focus on biomass value chains, whereas others emphasise instrumental approaches that transcend sectors. Naturally, given the stage of technological and market development in the majority of bioeconomy sectors, most of the countries prioritise research and development (R\&D) activities. In addition, most national approaches feature initiatives related to knowledge-sharing and networks. This may include the funding and facilitation of networks or clusters, and the establishment of national/regional bioeconomy panels or sector-specific platforms.

Other aspects that are less prominent in the national strategies include networks that transcend sectors and national borders, e.g. for SMEs within the bio-refining or materials sectors; venture capital for scaling up promising solutions; new approaches to communications, education and vocational training; and more coherent policies at Nordic level. These efforts should not be overlooked, as many leading companies are now diversifying production lines: where previously the strategy was based on the mass production of relatively few bulk products, the focus is now on utilising all side-streams.

At Nordic level, the Nordic Council of Ministers has been working on the bioeconomy since 2012. It has been high on the agenda of several of the annual 

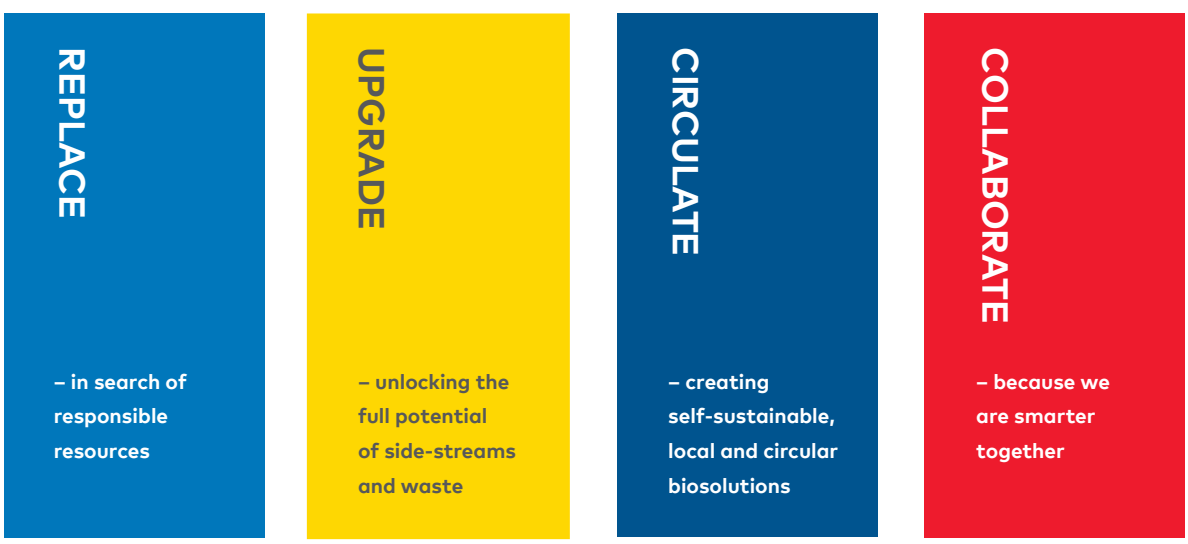

Strongholds of the Nordic bioeconomy based on four horizontal themes.

programmes for the Presidency of the Nordic Council of Ministers, and specific actions have been taken in the Arctic region, the North-West Atlantic and the Baltic Sea region. The bioeconomy also forms part of other policy initiatives, e.g. in Agenda 2030 and the work of the Nordic Council of Ministers for the Environment and Climate and Energy.

In 2017, the Nordic Council of Ministers published a selection of 25 Nordic bioeconomy case studies ${ }^{3}$ based on four horizontal themes: REPLACE, UPGRADE, CIRCULATE, and COLLABORATE. Together, these themes describe the direction in which all bioeconomy sectors need to move in order to achieve the sustainable production and use of our biological resources. They underline that the bioeconomy represents a paradigm shift from the traditional sectors of agriculture, forestry and fisheries to a more holistic approach, in which the demarcation lines between the sectors are less clear-cut and significant.

The Nordic institutions (particularly NordForsk, Nordregio, Nordic Innovation, NordGen, Nordic Forest Research and the Nordic Joint Committee for Agriculture and Food Research) have also made significant contributions to policy development on the Nordic bioeconomy. However, there is still untapped potential for streamlining Nordic efforts and aligning them more closely with other Nordic and national initiatives.

The Nordic countries all have their own different points of departure and different potential, based on biomass accessibility, production and economic structures. This programme does not, therefore, attempt to identify or promote specific, prioritised biomass value chains. Instead, the focus is on how the Nordic countries can maintain and strengthen their leading position in the conversion of different types of biomass into valuable and sustainable technologies, products and eco-services.

\footnotetext{
3 www.norden.org/25cases
} 


\section{5 actions to make the "new" Nordic bioeconomy a reality}

The Nordic bioeconomy is developing rapidly, and it is vital that the Nordic countries' national and regional policies follow and support this development. The Nordic Bioeconomy Panel has identified a set of actions that contribute to Nordic policies and business solutions for a competitive, profitable and sustainable bioeconomy. Although the focus is on the Nordic Region, many of the action points would benefit from a wider macro-regional approach, for example with reference to the Arctic, the Baltic Sea region or the EU as a whole.

The aim is not only to strive for sustainable change in the Nordic bioeconomy, but also to identify areas in which the Nordic Region can benefit from synergies, move faster and join forces to achieve critical mass in research and innovation, and in relation to creating larger Nordic "home markets". Areas of specific interest for the Nordic Region include digitalisation, biorefineries, wooden construction, packaging bioenergy, marine resources, and the borders between aquatic and terrestrial ecosystems.

The actions can be divided into three broad categories:

\section{- INNOVATE}

- ACCELERATE

- NETWORK

All of these aim to address global challenges such as climate change, biodiversity loss, feeding a growing population and reducing waste. The objectives are to create synergies from integrating national Nordic strategies and to increase visibility and awareness regarding the potential benefits of the

Nordic bioeconomy. 



\section{Supporting research, innovation and human capital}

1. HIGHER R\&D FUNDING throughout the value chain. This can be done within Nordic co-operation - NordForsk and Nordic Innovation play a particular role in terms of providing R\&D funds - but other Nordic organisations (e.g. the Nordic Investment Bank or Nordic Forest Research and the Nordic Joint Committee for Agricultural and Food Research) can also contribute. At EU level, more R\&D funding is being made available in this field, which will speed up progress toward the Nordic bioeconomy.

2. MORE COHERENT POLICIES and alignment of existing strategies and R\&D programmes, both nationally and internationally. The pan-Nordic institutions can make a significant contribution by aligning their strategies and focusing their activities to facilitate sustainable change in the bioeconomy. National institutions and programmes should be encouraged to create synergies from international collaboration in the Nordic Region, in order to project a stronger voice in the EU on issues related to the bioeconomy.

3. INVESTMENT SUPPORT to scale up promising demo and pilot projects within the Nordic bioeconomy. An investment fund to bridge the gaps between pilot and demonstration, and between demonstration and industrialisation, could boost interest in establishing bio-based start-ups and subsequently help them scale up. This could be achieved, for example, by establishing strategic partnerships with existing financial institutions or via new "green" venture capital in line with the Nordic Green Bonds.
4. NEW EDUCATIONAL OPPORTUNITIES for young people in the bioeconomy field. This could take the form of such initiatives as innovative education approaches in the lower levels of the school system; Nordic bachelor and master programmes and apprenticeships; and exchanges of PhD students. There is also need for new vocational training systems taking into account trends like interdisciplinary value chains and new technologies.

5. PROVIDE INTELLIGENCE on the Nordic bioeconomy. This includes mapping the interaction between biological by-products and the development of second- and third-generation biofuels; how the bioeconomy can most efficiently contribute to the reduction of greenhouse gases; and market analysis and mapping of Nordic/Baltic positions of strength within the bioeconomy. 


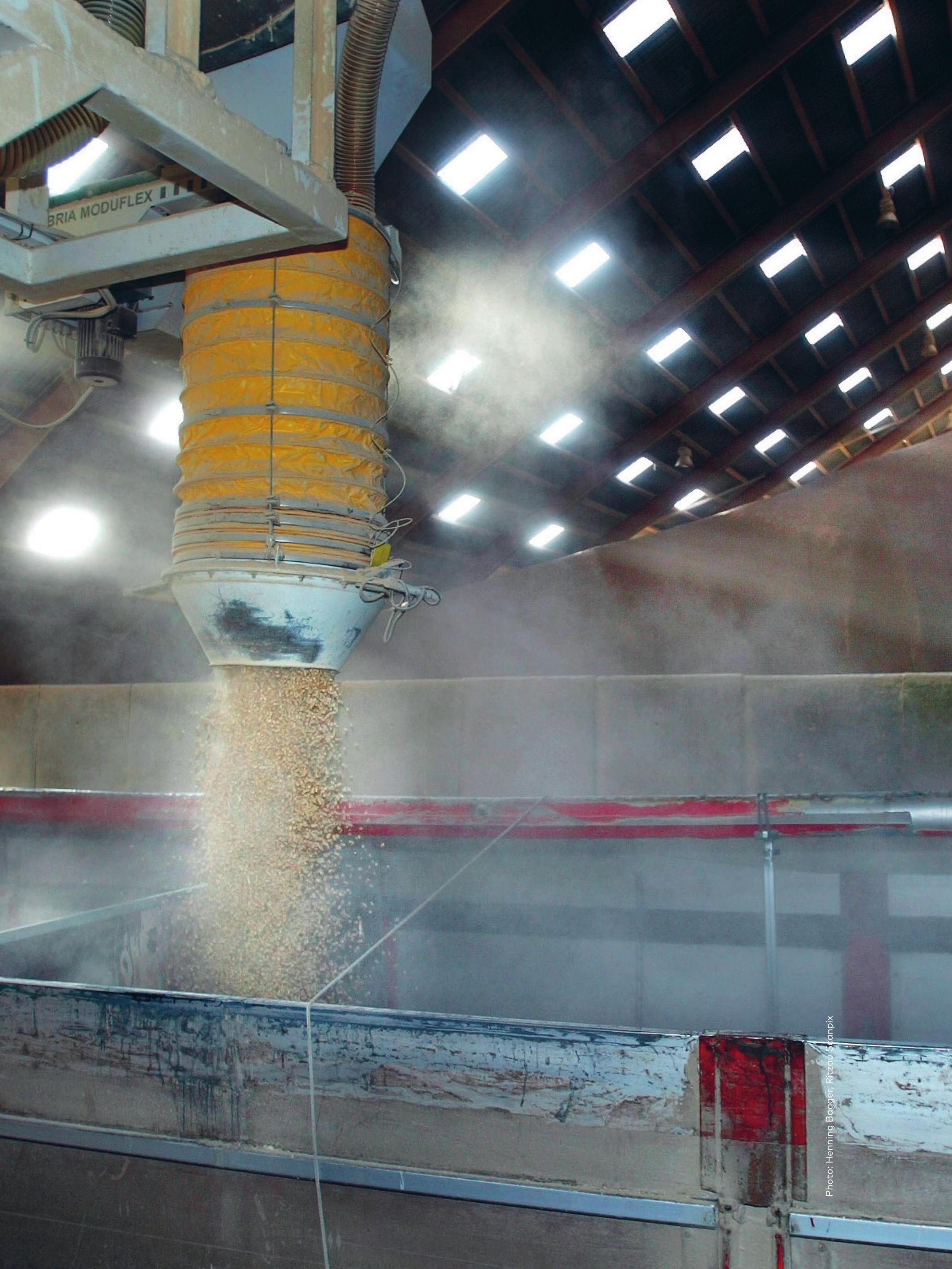




\section{Policies and market development}

6. TARGETED PUBLIC PROCUREMENT is a powerful tool for achieving market-driven change by generating demand for new solutions and bio-based products. It would be of great benefit to the bioeconomy if public-sector agencies (at both national and EU level) were required to comply with certain sustainability criteria in their procurement policies, such as by prioritising bio-based chemicals, materials and energy. Through such mechanisms, the Nordic public sector could drive demand for a sustainable bioeconomy. This could also be combined with subsidies and/or tax incentives to promote investments and business development, with a view to making new production economically competitive.

7. REGULATORY FRAMEWORKS can play an important role in supporting green alternatives to fossil-based products and services. The aim should be to help make markets more stable in terms of the price and availability of biomass, e.g. by setting policy targets for the use of biomass, for the mandatory use or prohibition of products, or even direct financial incentives in the form of taxes on products to be discouraged and subsidies for new solutions. Governments can also promote sustainable development through the consistent use of life-cycle analyses. Local authorities can also play an important role in setting standards and making sustainable choices.
8. LABELLING AND CERTIFICATES are normally based on companies' voluntary participation and involvement. The role of government (local, national or international) is to set coherent certification frameworks and harmonise labelling and standards, which in turn creates consumer-driven market pressure. At the Nordic level, this approach has proven effective in the Nordic eco-labelling scheme. ${ }^{4}$ Labelling or certificates could pave the way for a Nordic bio-based brand that emphasises sustainability.

9. REGIONAL INNOVATION STRATEGIES and smart specialisation strategies are important tools with which to facilitate the development of new industries and technologies based on the utilisation of biological resources. The bioeconomy and the circular economy rely on the availability of bioresources or appropriate side-streams. Local strategies, tied to EU strategies, are therefore at the core of the OECD's New Rural Paradigm, and can contribute to increased prosperity, social inclusion and gender equality.

\section{PROMOTING CROSS-BORDER FREEDOM OF MOVEMENT OF PRODUCTS between the Nordic countries to increase the commercial viability of innovative bioeconomy products in the long term. Many value chains in the new bioeconomy are im- mature, and expanding companies face challenges in terms of securing access to larger markets that will generate the necessary turnover and satisfy investors.}

\footnotetext{
${ }^{4}$ www.svanen.se
} 

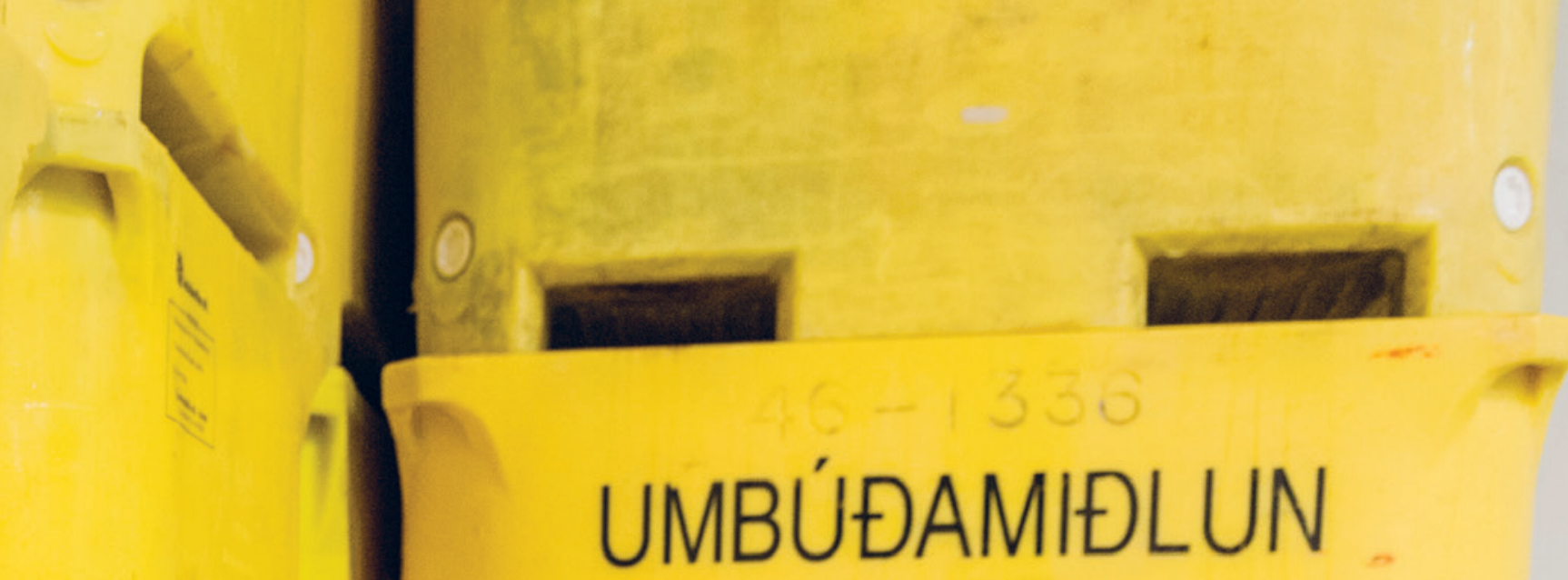

UMBÚĐAMIĐLUN

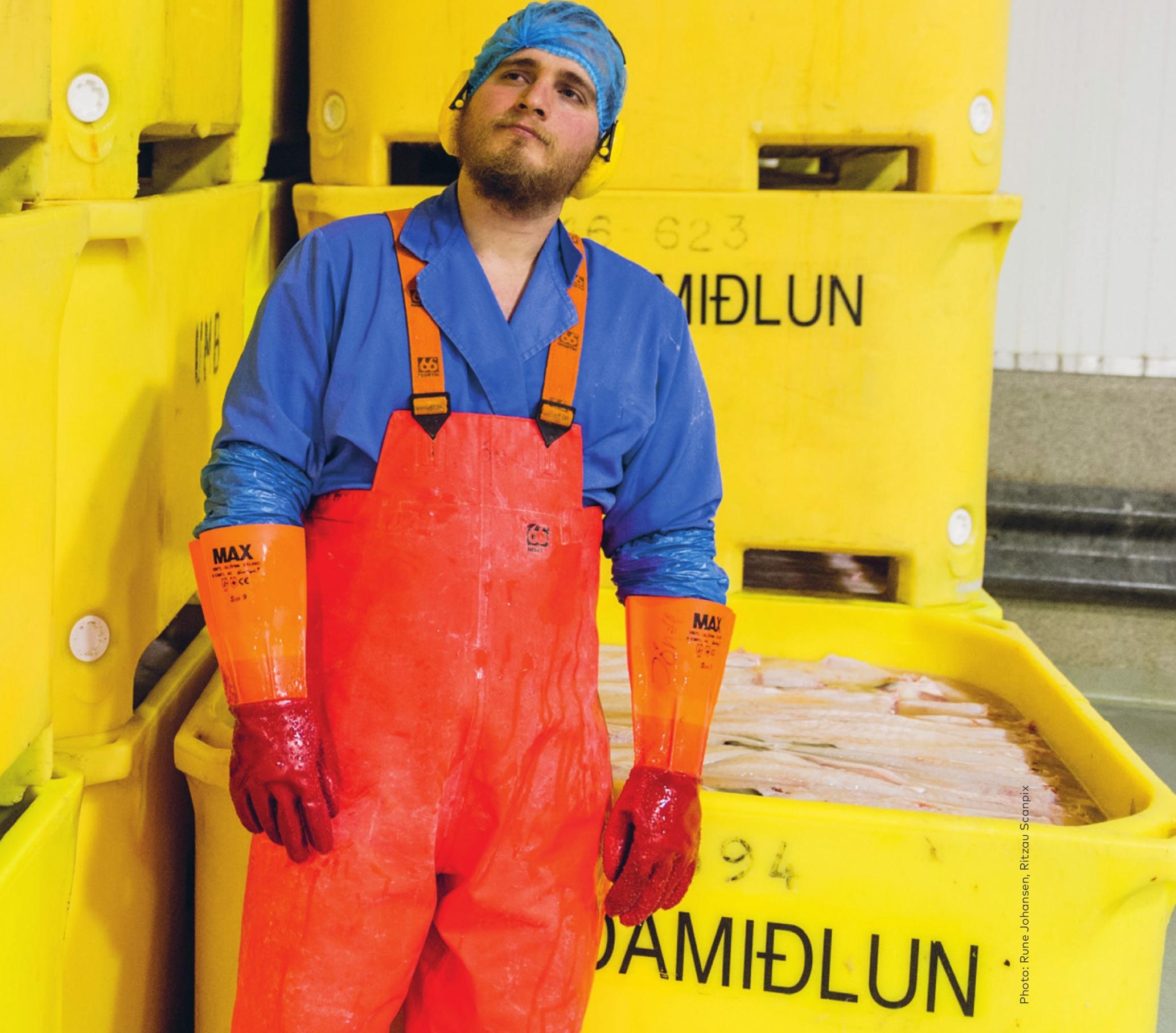




\section{Forging new and stronger connections}

11. SUPPORT BIOECONOMY CLUSTERS acrosS the Nordic Region. Industrial clusters and publicprivate partnerships are an established tool for sharing best practices and facilitating development and innovation. For example, SME clusters around bio-refineries can simplify logistics and create synergies by using each other's side-streams and by pooling energy resources. Some examples of successful cluster collaboration already exist at national level and can serve to inspire new Nordic initiatives that transcend sectors and national borders.

\section{OPEN ACCESS TO TEST AND DEMONSTRA-} TION CENTRES for the bioeconomy and secure open access across borders. This can be done through public-private partnerships (PPP) or solely through public or private funding. The lack of test and demonstration facilities can often be a barrier for innovation and co-operation, especially in rural areas. Many rural areas lack easy access to innovation centres, which could often be provided by means of digital solutions or other innovative structures. The centres themselves can also become important hubs for local expertise and provide valuable employment opportunities.
13. MACRO-REGIONAL CO-OPERATION AND PLATFORMS can serve to expand Nordic networks, facilitate business development and investment, and communicate the Nordic agenda on the sustainable bioeconomy. The Nordic Council of Ministers engages in macro-regional co-operation with the Baltic Sea and the Arctic regions. The Nordic institutions also have an important role to play in developing and maintaining these connections in relation to the bioeconomy.

14. BOLSTERING NETWORKING ACTIVITIES to share contacts, information and knowledge, and facilitate co-operation between industry, academia, public authorities and the financial markets. The network should focus on providing expert assistance on commercialisation, marketing, product registration, funding opportunities, etc. It could consist of a virtual network (e.g. of Nordic stakeholders) or be more formally structured.

15. NORDIC IMPACT AND BRANDING to increase Nordic bargaining power and influence in international forums, e.g. the UN's Paris Agreement, EU, WTO, etc. The Nordic countries are frontrunners in many aspects of the bioeconomy, and could contribute greatly to bioeconomic development in Africa or Asia. The Nordic bioeconomy could also be developed as a specific brand, aimed at influencing consumer behaviour, attracting young people to the bioeconomy sector and promoting exports. 


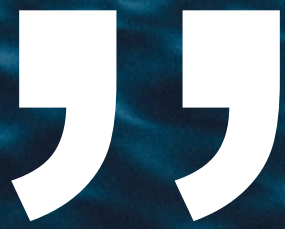

Plastic bottles

take more than 700

years to degrade.

Seaweed packaging

bio-degrades in

soil in four to

six weeks 


\section{The way forward}

This Strategic Programme for Strengthening the Nordic Bioeconomy 20182022 contains 15 action points aimed at promoting a sustainable bioeconomy in the Nordic Region. It would not be reasonable to expect to fulfil all of them by 2022, but they signal the starting point and the strategic direction of Nordic efforts to develop the bioeconomy. Initial steps should focus on shortterm goals that can be achieved by the soft measures and funding already at hand, for example:

$\rightarrow$ Knowledge exchange and strategic partnerships. This could include continuing the work of the Nordic Bioeconomy Panel; starting a dialogue with relevant stakeholders to develop new education and training programmes; and setting up a digital Nordic/Baltic Bioeconomy Portal to facilitate public-private partnerships and cluster-to-cluster collaboration.

$\rightarrow$ Analysis and research to identify areas where the Nordic countries have particular positions of strength, as well as to map investment priorities, market potential and environmental impacts of the bioeconomy. Important areas include digitalisation, climate work, social inclusion and gender equality.

$\rightarrow$ Policy development at Nordic and international levels to align national policies and establish an active dialogue with the EU and other international players on how to promote the development of a sustainable bioeconomy. 


\section{APPENDIX}

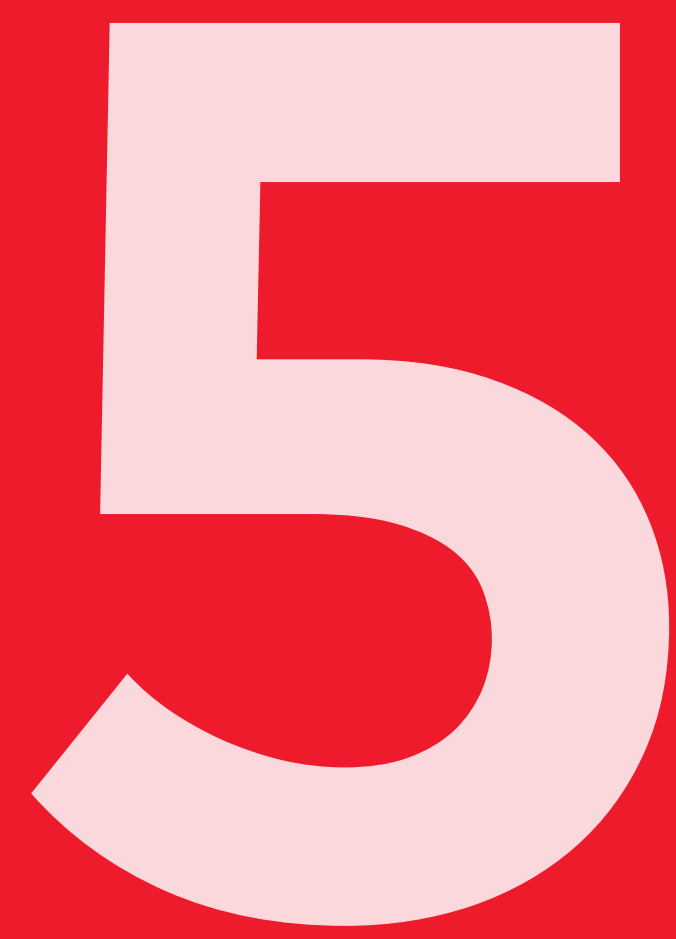

Principles for

a sustainable

Nordic Bioeconomy 


\section{Sustainable Nordic bioeconomy}

If managed with strict adherence to sustainable development principles, the bioeconomy will be the key to pursuing many of the Sustainable Development Goals (SDGs). Conversely, if the bioeconomy leads to a depletion of resources, degradation of the environment, loss of biodiversity and social injustice, it should not be pursued. The Nordic Council of Ministers has therefore set out five principles aimed at ensuring the development of a sustainable Nordic bioeconomy.

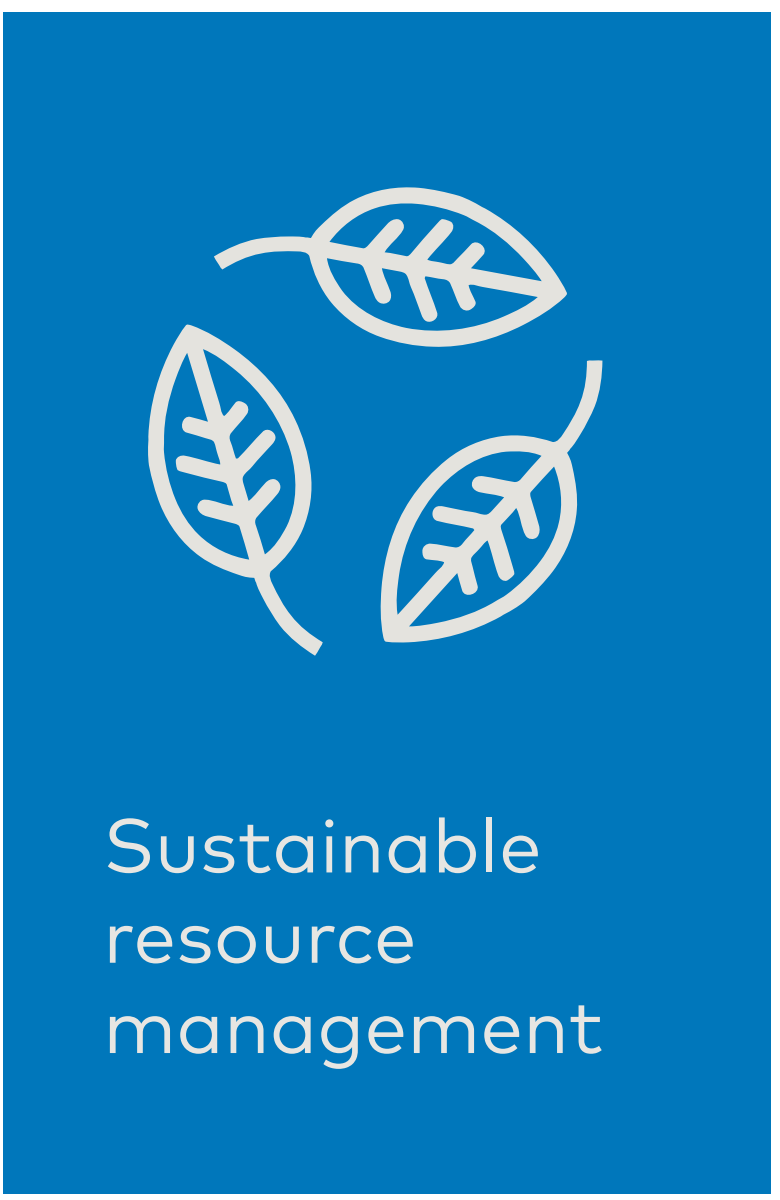

The proposed principles are a step towards developing common ground and good practices for a sustainable bioeconomy in the Nordic Region, and may inspire other regions to follow suit. They can also serve as a reference point for collaborations with other parties (e.g. national governments, the $\mathrm{FAO}$ and the $\mathrm{EU}$ ) on strengthening the bioeconomy.

\section{RESPONSIBLE USE OF OUR SHARED RESOURCES}

- The Nordic bioeconomy should contribute to sustainable production and harvesting of bio-resources

- The Nordic bioeconomy should contribute to upgrading residues, side-streams and waste to higher value products and services, in order to optimise the utilisation and value of biomass

- The Nordic bioeconomy should contribute to increased output from biomass through resource efficiency and digitalisation 

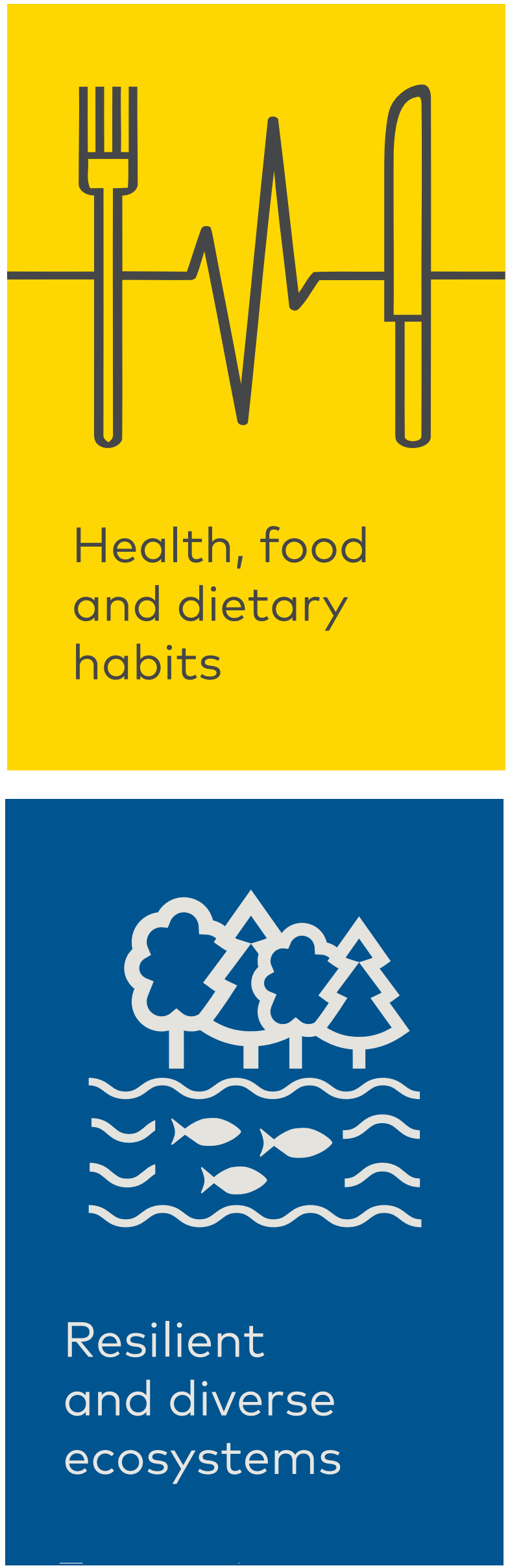

\section{SAFE, SUFFICIENT AND NUTRITIOUS FOOD FOR ALL}

- The Nordic bioeconomy should encourage innovation in food production systems

- The Nordic bioeconomy should contribute to improved general health and nutrition by developing new, sustainable and healthy food and pharmaceutical products (for those in need)

- The Nordic bioeconomy should guarantee food security and safety in all parts of the food chains

\section{A LIVEABLE PLANET}

- The Nordic bioeconomy should support measures to cut air pollution and reduce greenhouse gas emissions, and refine renewable alternatives to fossil-based products and processes

- The Nordic bioeconomy should enhance biodiversity both on land and in water

- The Nordic bioeconomy should restore and sustain soil fertility, and protect water quality, by lowering water usage and by recycling via a proper purification process 


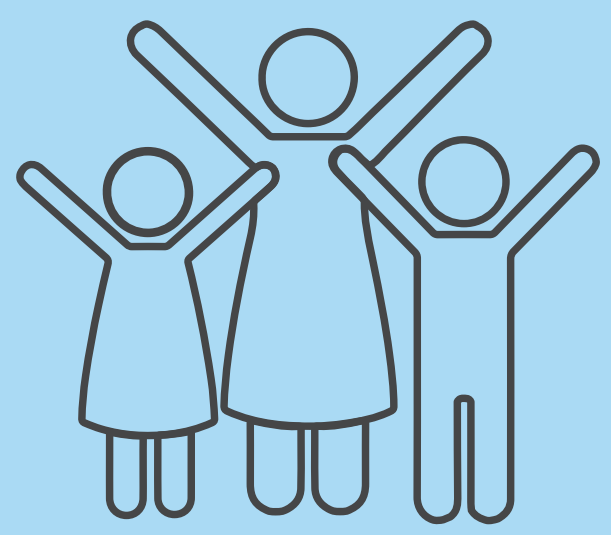

Inclusive

economic and social prosperity

\section{SUSTAINABLE FAIR SOCIETIES}

- The Nordic bioeconomy should contribute to the creation of equal and fair new jobs for women and men, and sustain existing ones, especially in rural and coastal areas

- The Nordic bioeconomy should contribute to the development of sustainable and financially viable business models

- The Nordic bioeconomy should provide rural and urban areas with environmental, social and economic opportunities, and encourage new partnerships at local, regional, national and global level

\section{CHANGING MINDSETS AND CONSUMER BEHAVIOUR}

- The Nordic bioeconomy should provide infrastructure that facilitates the reuse, recycling and upcycling of bio-based products, while limiting waste

- The Nordic bioeconomy should encourage green procurement in both the public and private sectors, as well as in private households

- The Nordic bioeconomy should contribute and commit to education in and awareness of sustainable practices, from kindergarten to university 


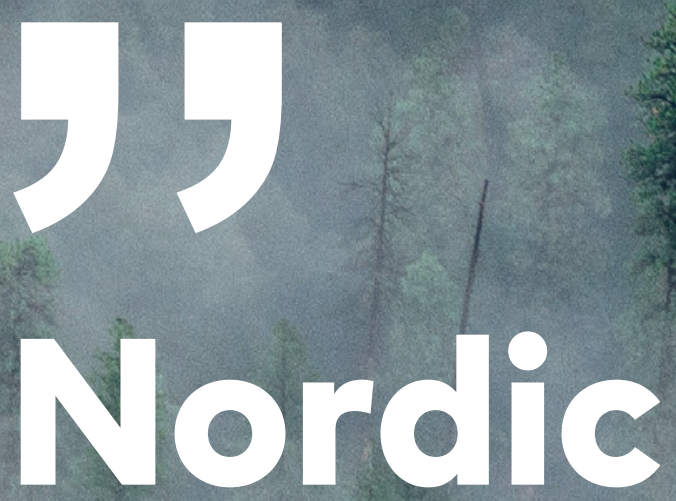

bioeconomy

is eloout

sustelineble

chonge

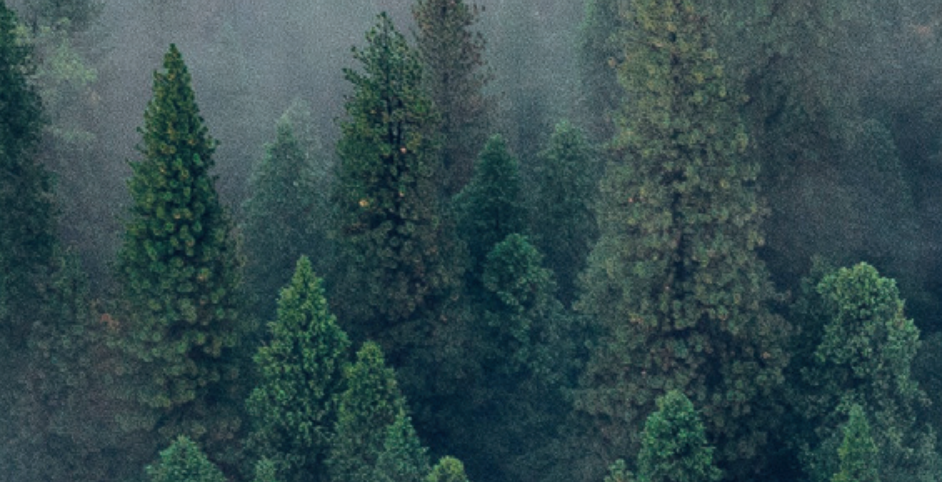

13/19 


\title{
Members of the Nordic Bioeconomy Panel
}

\author{
Country representatives \\ Hörður G. Kristinsson, chair - Iceland \\ Casper Linnestad - Norway \\ Henrik Leth and Lisbeth Due Schönemann-Paul - Greenland \\ Lene Lange - Denmark \\ Liisa Saarenmaa - Finland \\ Ólavur Gregersen - Faroe Islands \\ Stefan Källman and Jan Svensson - Sweden \\ Sölve Högman - Åland \\ Observers \\ Elisabeth Smith - Nordic Innovation \\ Gunnel Gustafsson - Nordforsk \\ Hans Jørgen Koch - Nordic Energy Research \\ Helge Paulsen - Nordic Working Group on Fisheries \\ Johan Elvnert - European Forest-based Sector Technology Platform \\ Jonas Rönneberg - Nordic Forest Research \\ Jukka Teräs - Nordregio \\ Karen Refsgaard - Nordregio \\ Kjell Ivarsson - Federation of Swedish Farmers \\ Lise Lykke Steffensen - The Nordic Genetic Resource Centre \\ Niels Gøtke - Danish Agency for Sciences, Technology and Innovation \\ Per Hansson - The Nordic Joint Committee for Agricultural and Food Research \\ Sirpa Kurppa - Natural Resources Institute Finland (Luke) \\ Torill Meistad - Nordic Energy Research
}

A special thanks to Dr. Dr. h.c. Christian Patermann, the Danish think tank Sustainia and Innovasjon Norge for their valuable input.

Project secretary

Nordic Council of Ministers' Secretariat

Contact

Torfi Jóhannesson, torjoh@norden.org, Nordic Council of Ministers

Marte Mathisen, marmat@norden.org, Nordic Council of Ministers

For more information please visit: www.norden.org/bioeconomy 
Nordic Council of Ministers

Nordens Hus

Ved Stranden 18

DK-1061 Copenhagen K

www.norden.org

THE NORDIC BIOECONOMY PROGRAMME presented in this document combines environmental, social and economic ambitions for a more sustainable Region. The bioeconomy is of fundamental importance to the national economies of the Nordic countries, and especially important for rural development in large parts of the Region. The programme aims to create new industries and value chains and to facilitate and guide the transition of bio-based industries into technologically advanced industries, and to optimise the production and value creation of biomass. The programme sets out a vision for the Nordic bioeconomy based on four pillars:

- competitive bio-based industries

- sustainable resource management

- resilient and diverse ecosystems

- inclusive economic development

To reach this vision, the programme defines 15 action points under three thematic areas: Innovate - Accelerate - Network. The focus is on the development of new policies at regional, national and Nordic levels, for increased funding, better education, labelling and certificates, bioeconomy clusters and several other areas. The programme also contains an appendix with sustainability principles that can be seen as a step towards developing common ground and good practices for a sustainable bioeconomy in the Nordic Region. 